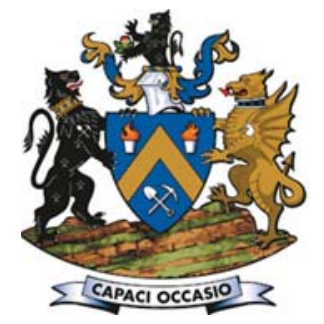

\title{
Towards safer mining: scientific measurement approaches that could be applied for imaging and locating the buried container lamp-room at Lily mine
}

\author{
by I. Hussain*, F.T. Cawood*, and S. Ali
}

\section{Synopsis}

When the crown pillar at Lily mine collapsed on 5 February 2016, a lamproom in a container on surface was engulfed in the sinkhole that formed, trapping three miners who were in the lamp-room at the time. In situations like this, it is imperative to locate and rescue the missing miners before the window of opportunity to find them alive closes. The Wits Mining Institute (WMI) at the University of the Witwatersrand was requested to assist with suggestions, and a conceptual study was undertaken to identify techniques that were likely to be successful. Several techniques that have the potential to locate the position of the container were identified, but the typical noise in the form of steel objects, mine cavities, and a combination of broken and solid rock in a complex geographical and geomechanical environment will pose significant challenges.

Keywords

safety, leadership, human factors, human error, human behaviour, safety culture. of knowledge that can be consulted during mine disaster and rescue management.

\section{Overview of the mine, the event, and the broad technology approaches}

Lily Mine is about $38 \mathrm{~km}$ southeast of Nelspruit and $25 \mathrm{~km}$ northeast of Barberton in the Mpumalanga Province of South Africa. The study area is shown in Figure 1.

Underground mining remains a high-risk activity prone to accidents and sometimes mine disasters. The costs associated with an accident can be so substantial that mining operations may be infeasible following the event. One such accident occurred at the Lily Mine on 5 February 2016, when the crown pillar protecting the underground and surface workings collapsed. The lamp-room, which was housed in a steel shipping container, fell into the sinkhole that formed, with three miners trapped inside. Two metallic water tanks, one $550 \mathrm{kVA}$ generator, and many other metallic objects went down the sinkhole due to the abrupt and unexpected nature of the accident. The reasons for the collapse are still under investigation. The collapsed area was declared unsafe and unstable by the mine and the Chief Inspector of Mines, South Africa.

On 25 February 2016 the Mine Health and Safety Council (MHSC) of South Africa requested the Wits Mining Institute (WMI) at the University of the Witwatersrand to suggest methods that could be used to locate the lost container. A quick and promising response was received from all over the University. The ideas suggested included using an unmanned aerial vehicle (UAV) equipped with a magnetometer and digital camera, detecting the underground cavity with ground penetrating radar (GPR), using acoustic equipment like geophones to detect sound, electrical resistivity tomography, thermal

* University of the Witwatersrand, South Africa.

† NUST College of Civil Engineering, Risalpur Campus, Pakistan.

(c) The Southern African Institute of Mining and Metallurgy, 2018. ISSN 2225-6253. Paper received Jan. 2017; revised paper received Dec. 2017. 


\section{Towards safer mining: scientific measurement approaches that could be applied}

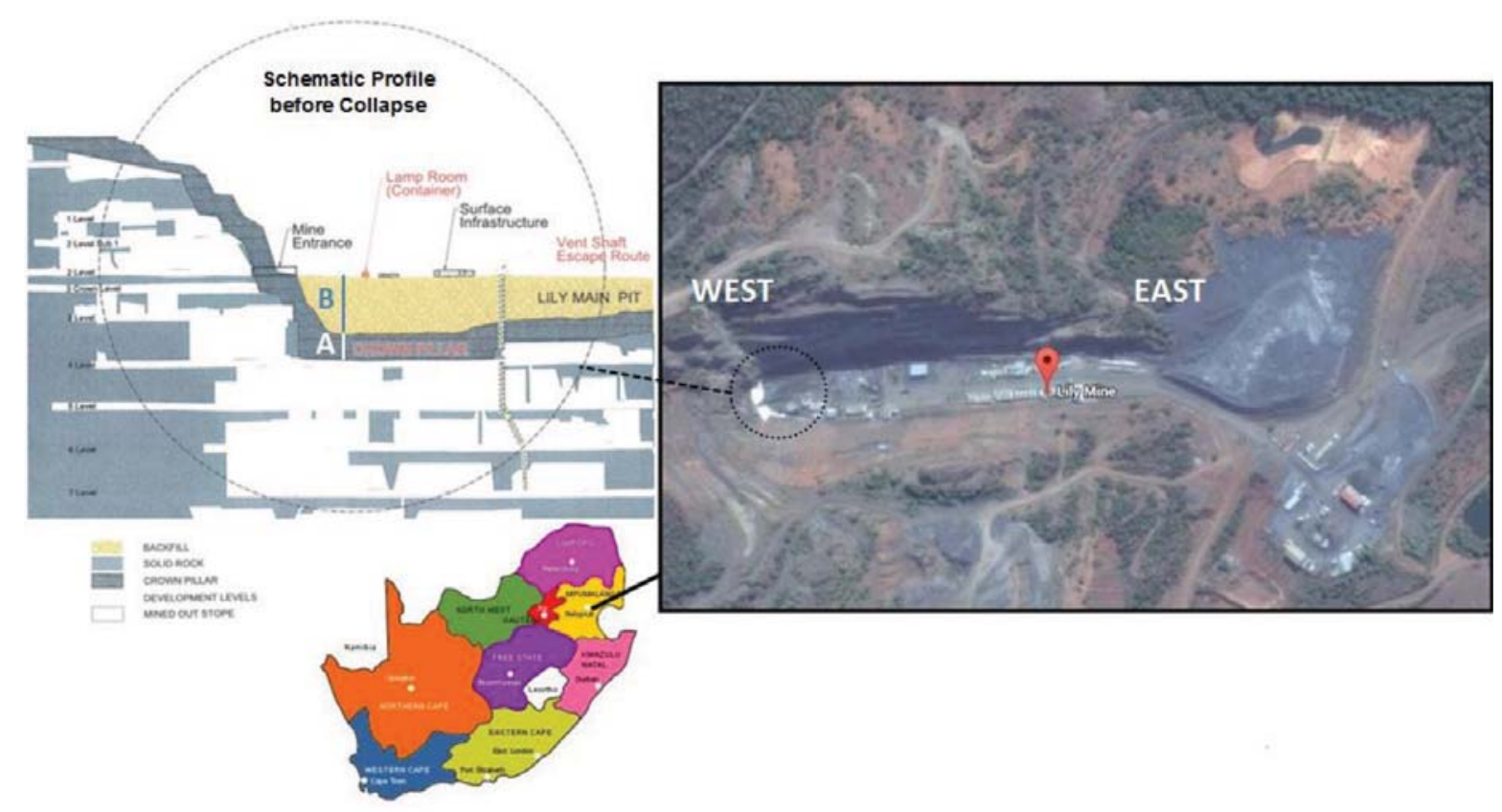

Figure 1-Location map of the study area. The height of the crown pillar (A) and backfill (B) is approximately $35 \mathrm{~m}$

imaging, through-the-earth communication systems, electrical resistivity metering, and simulating the movement of the container using 3D geographical and numerical simulation software. These solution-based ideas were then divided into two distinct groups-those used to locate the container and those used to simulate the movement of the container through 3D fluid flow and advanced numerical modelling software, as used to find trapped persons after an avalanche in mountainous areas. At a visit to Lily mine on 9 March 2016, the WMI team suggested a two-way strategy going forward:

> First, a temporal 3D modelling approach using software technology

- Second, a scientific measurement and testing approach, which is the topic of this paper.

\section{The role of technology for imaging and locating buried objects in underground mine disasters}

Despite the availability of modern rescue equipment and technologies for tracking and monitoring, the harsh underground environment causes most technologies to give questionable results during mine-related rescue operations (Mine Safety and Health Administration, 2010). This study identifies technologies for imaging and locating buried objects. It also evaluates some suitable technologies for finding steel objects, underground voids, and communication devices. The compiled record of suitable technologies would be useful for future mine search-and-rescue operations.

\section{Conceptual approach followed for detecting the lamp-room container}

Fundamentally, the objective of the study is to apply science and technology to determine the likely locations of the container, the communicating devices of the miners inside the container, and of course the missing miners. The following specific objectives were set:
- Identify potential technologies that can locate the lamproom container

> Apply a combination of science and technology to determine the location of the lamp-room container

- Test certain technologies in a mining environment and record the findings

- Compile a record of suitable technologies for future mine search-and-rescue purposes

- Collect information that will assist a research project to understand what happened at Lily Mine.

\section{Potential technologies for imaging and locating subsurface objects}

The fundamental principle behind such imaging technologies is to input energy into the earth and to then analyse the reflected energy. Interpretation of the reflected energy can indicate the horizontal position of the object of the search. The following sections discuss electromagnetic (EM), magnetic, infrared thermography, resistivity, seismic, ground penetrating radar (GPR), micro-gravitational, and communications approaches, which are based on different geophysical principles.

\section{Magnetic/electromagnetic (EM) approach}

The magnetic approach utilizes variations in the intensity of the Earth's magnetic field. The local geology at Lily mine includes highly magnetic rock units, and the magnetic noise from the two water tanks, one $550 \mathrm{kVA}$ generator, and many other metallic objects that were engulfed by the sinkhole would pose additional challenges in interpreting the results.

\section{Pipe and cable locator}

The pipe and cable locator works on the principle of a conductive or inductive mode transmitter emitting an EM wave (generally $50 \mathrm{~Hz}$ to $480 \mathrm{kHz}$ ) and a receiver that detects the reflected waves from underground objects (American Society of Civil Engineers, 2002). If the 


\section{Towards safer mining: scientific measurement approaches that could be applied}

transmitted EM wave comes in contact with a metallic object, an electromagnetic current is induced in that object and the receiver detects and processes the induced magnetic field, indicating the presence of the object by means of an audible or visual signal. The available pipe and cable locator in the market can detect underground utilities up to $6 \mathrm{~m}$ depth (Amprobe, n.d.). This method cannot image nonmetallic objects, unless they are marked with metallic tape or wire. Considering the conditions at Lily mine, where the container is likely to be deeper than $6 \mathrm{~m}$, and the surface area directly above the container is too unstable to access, pipe and cable locators are unlikely to be successful.

\section{Electronic marker system (EMS)}

In this technology, a transmitter emits radio frequency signals to an electronic marker that was fitted to the facility at the time of construction or installation. Different frequencies can be used to assign to and locate different buried objects. The specially designed markers can be detected even in the presence of power lines, metallic conductors, and fences. The available EMS system in the market can detect underground utilities up to $3 \mathrm{~m}$ depth (3M Infrastructure Protection Division, 2012). The short range and the fact that the Lily mine lamp-room container was not equipped with an EMS marker eliminate this technology. It has, however, wider applications than the pipe and cable locator because the receiver can also work from underground.

\section{Metal detector}

The metal detector works by transmitting an AC (alternating current) magnetic field into the ground and then the receiver analyses the corresponding field (American Society of Civil Engineers, 2002). The search coil senses the change in the magnetic field caused by a conductive metal object. The reflected magnetic field from the magnetic objects is slightly different to that of the surrounding soil. The available metal detectors in the market have a range of up to $6 \mathrm{~m}$ depth (Benson, Glaccum, and Noel, 1984). Considering its longer range and the fact that it can be operated underground, a good quality metal detector could be sourced to alert the rescue team when they come in close proximity to metal objects.

\section{Magnetometer}

This is an instrument that records the Earth's magnetic field. It uses two methods for imaging and locating underground utilities (American Society of Civil Engineers, 2002). The first method is total field measurement, which is useful for searching for metallic objects over large distances in the absence of power lines, vehicles, railroads, or other sources of interference. The second method is gradiometric measurement, which is useful for detecting shallow metallic objects. The depth of penetration greatly depends on the field strength and the average detection depth is 3-6 $\mathrm{m}$ (Dodge and Anspach, 1995). It can detect larger metallic objects up to 20 m deep (Benson, Glaccum, and Noel, 1984). Although a magnetometer has potential, the simplicity of a metal detector makes it a more flexible option.

\section{Ground penetrating radar (GPR)}

GPR works on a reflection technique that uses highfrequency electromagnetic waves (typically $10-1000 \mathrm{MHz}$ ) to acquire subsurface information. It responds to changes in electrical properties (i.e., conductivity and dielectric constant), which are a function of soil, rock material, and moisture content (SubSurface Surveys \& Associates Inc., n.d.). The technology can also be mounted on a moving vehicle or a drone. GPR waves can reach 30-40 m in lowconductivity materials such as dry sand or massive, dry concrete or granite (Jeong et al., 2003).

\section{Ground Penetrating Analyzer GPA 3000}

This image analyser gives a visual indication of size, shape, and even the type of metal detected (KTS-Electronic, 2016). It also gives an exact distance from the detector to the top of target metal down to a depth of $25 \mathrm{~m}$.

This technology has potential for imaging and locating the buried container lamp-room (and other objects) at Lily mine, but its effectiveness when used underground needs to be established.

\section{Electrical resistivity tomography}

Electrical resistivity tomography using intrinsic properties, i.e., electric resistance and stiffness contrast of the subsurface materials, has been successfully used to detect leachates, groundwater, bedrock, stratigraphic layers, buried objects, cavities, and utilities (Jusoh, 2010). Besides being nondestructive, electrical resistivity geophysical techniques can be implemented quickly, are relatively inexpensive, and have larger coverage in both the horizontal and vertical extents (Khatri, Shrivastava, and Chandak, 2011). A 2D illustration of the resistivity results at a project site is shown in Figure 2. A 3D manifestation of an archeological investigation carried out to locate a grave is shown in Figure 3. With a suitable number, spacing, and arrangement of arrays, the electrical resistivity method can be used to locate buried objects up to great depths (the depth of penetration equals a third to a quarter of the horizontal separation of the electrodes at ground surface).

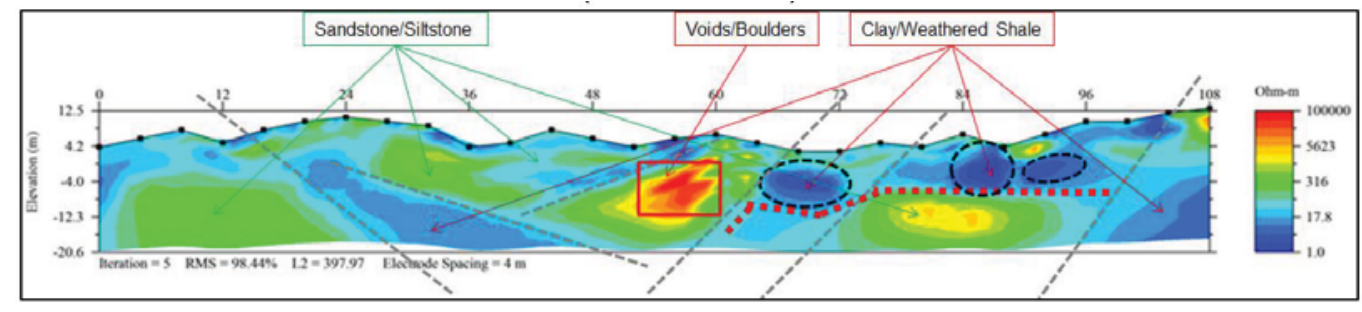

Figure 2-A 2D subsurface characterization of materials on the basis of difference in electrical resistivity 


\section{Towards safer mining: scientific measurement approaches that could be applied}

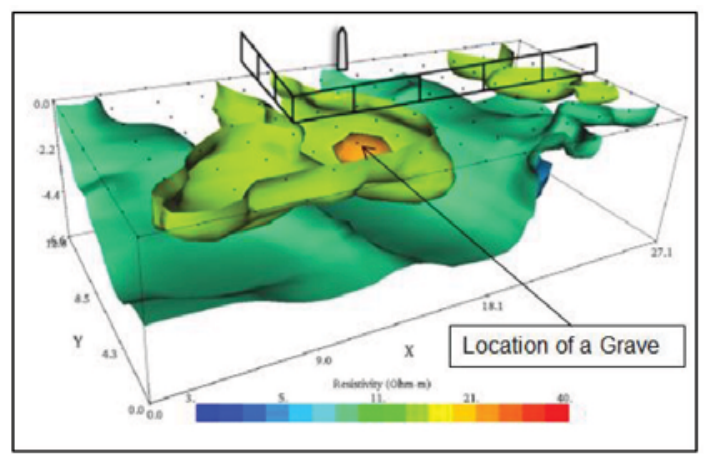

Figure 3-3D illustration of a grave located using electrical resistivity method (Advanced Geosciences, Inc., 2016)

\section{Infrared (IR) thermography}

IR thermography detects infrared radiation emitted from an object and converts the signal to visible wavelengths on the electromagnetic spectrum. Each object has different thermal characteristics. This method is effective for finding buried utilities that have different thermal characteristics from the surrounding ground. It cannot measure the dimensions, but relative sizes of objects can be deduced (Jeong et al., 2003). This method does not require ground contact, making it suitable as a remote sensing technology. Figure 4 shows an example of a thermal image of underground pipes as observed from a drone.

\section{Satellite IR imagery}

Satellite images are of benefit to Earth scientists due to the sensor responding to multiple spectral bands, which allows scientists to interpret wavelengths that cannot be seen by the human eye, such as near infrared, short-wave infrared, and thermal infrared, to identify anomalies (Satellite Imaging Corporation, 2013). Multispectral imaging and thematic mapping allows researchers to collect data on the reflection and absorption properties of soils, rock, and vegetation. This data could be utilized to interpret actual surface lithology to identify clays, oxides, and soils from satellite images. This method could be useful for imaging and locating the buried container lamp-room at Lily mine.

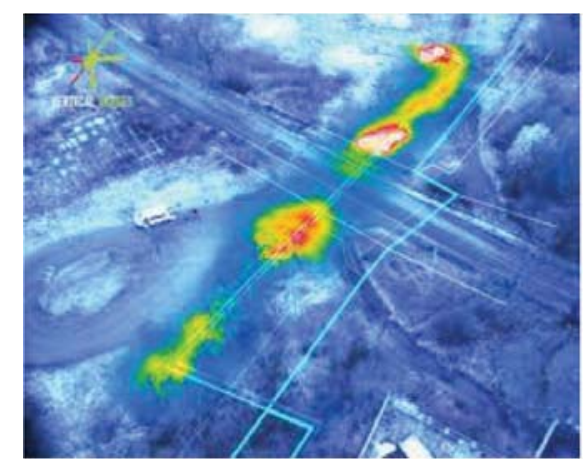

Figure 4-Thermal image for inspecting underground pipes (Workswell, 2016); The maximum measurement distance depends on the distanceto-spot ratio of the camera and the target size, i.e. D/S ratio $x$ Target size = maximum measurement distance

\section{IR camera}

Handheld infrared cameras can also be used for obtaining IR imagery. Although a camera is also an option at Lily mine, satellite imagery is considered better because of the area coverage, availability, and affordability.

\section{Microgravity}

Microgravity techniques measure variations in the Earth's gravitational field for locating areas of contrasting densities (Mariita, 2007). This technique is useful for imaging and locating large utilities (or cavities) that are predominantly empty. A cavity represents a mass deficiency, thus a small reduction in the gravitational field, or negative gravity anomaly, is observed. Gravity anomalies are due to the differences in density of underlying material. This technique can detect and image anomalies up to a depth of $33 \mathrm{~m}$ (Jeong et al., 2003).

\section{SCINTREX CG5M gravimeter}

This gravimeter can detect gravity anomalies at depths up to about 30-40 m (Innogeo, 2013). The size of the measurement mesh depends on the depth and size of the anomaly. This technology has some potential for imaging and locating the buried container lamp-room at Lily mine.

\section{Seismic techniques}

Seismic techniques work on the principle that the seismic waves travel with different velocities in different materials, i.e. rocks, soils, and underground objects. Seismic waves penetrate the ground and the travel time of reflected/refracted seismic waves is observed by geophones (SubSurface Surveys \& Associates Inc., n.d.). A seismic wave is generated by an explosive shot, hammer, weight drop, or some other shock that induces vibration. The detectors are placed at regular intervals and measure reflected energy and time of arrival. The data is plotted on a time-distance graph from which the velocities and depth of different subsurface layers can be obtained. Figure 5 shows a seismic refraction tomography of a salt diaper in central Utah. The maximum depth of interest is usually about $12 \mathrm{~km}$ (Stark, 2008).

\section{Trapped person locator (TPL)}

The trapped person locator (TPL) instrument can detect and pinpoint the location of trapped persons. It amplifies the faint sounds made by the trapped victims (Elpam Electronics Ltd., 2014). It uses seismic sensors to convert ground motion into a voltage. Geophones can also amplify sound and can be used to listen to sounds generated by missing persons.

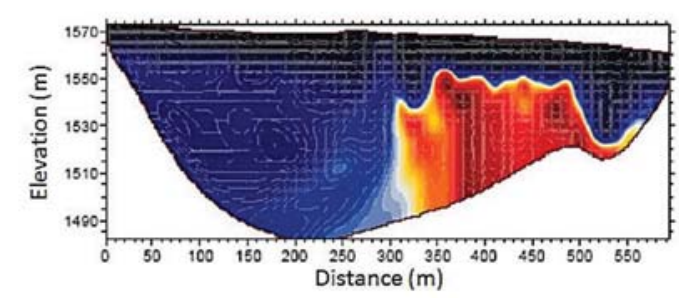

Figure 5-Seismic refraction tomography of a salt diapir in central Utah (Subsurface Surveys \& Associates, Inc., n.d.) 


\section{Towards safer mining: scientific measurement approaches that could be applied}

\section{Communications}

Mines and mineworkers have become highly connected over the last 30 years. This connectivity was accelerated by the take-off of the cellular phone industry. The increased upgrade of mine telecommunications systems and (personal) cellular phone use caused a decrease in the use of portable hand-held systems (hand-held transceiver or HT-commonly known as 'walkie-talkies'). Communications technology is by far the most practical way of establishing location, through either dialling-and-asking or tracking transponder signals.

\section{Cell phone calling and tracking}

The first step is to call on either HT or cell phone, and in the event that there is no response, the cell phone can be tracked through its unique International Mobile Subscriber Identity (IMSI) or International Mobile Equipment Identity (IMEI) number. It does not matter if the phone has a different SIM card or is switched off. This is the quickest and most efficient way of tracking the person carrying the phone if there is no answer. It is highly likely that the trapped miners at Lily mine had their cell phones with them at the time of the accident, as the lamp-room was located on surface. So determining the position of the lamp-room using the workers' cell phones becomes possible. The capability of this technology or how effective it will be under these circumstances is unknown because this technology is not publicly available.

\section{Through-the-earth (TTE) communication system}

TTE communication systems use significant transmitting power and large antennae to transfer low-frequency signals that can penetrate several hundreds of metres through solid rock (Bandyopadhyay, Chaulya, and Mishra, 2010). These systems are designed for use in mine emergencies when no other form of communication is possible. Therefore, TTE communication can be used in case of disaster recovery to locate trapped miners (Michael et al., 2012; Hussain et al., 2017). These systems support real-time voice, voice messages, data messages, and beacon signals but there are limitations on transmission rates due to the low operating frequency bands (Michael et al., 2012). This technology is not suitable as the Lily mine lamp-room was not 'intelligent', i.e. it was not equipped with a TTE communication system for mine emergencies.

Communication systems are the most likely method identified thus far, but the probability of success diminishes significantly over time. During the first few hours or perhaps days following the incident, it was critical to explore this option first before the window of opportunity of finding the trapped miners alive closed.

\section{Exploring some of the technologies identified}

Some of the technologies described in the previous sections were tested for locating and imaging the missing Lily mine lamp-room. The findings summarized in Table I. Although none yielded unambiguous results that led to finding the missing miners, the lessons learnt are documented here for future eventualities.

\section{EM approach: metal detector}

GyroLAG conducted an EM survey shortly after the collapse in the hope of locating the buried container. The metal detector was mounted on an unmanned aerial vehicle (UAV) that flew the area at a height of $20 \mathrm{~m}$ above the rubble because of difficult flying conditions. The survey identified eight possible positions after taking account of the 'noise' from the magnetic host rock (Figure 6). The initial results (left image) were of little use, but after the maps were georectified with the help of six ground-control points, the positions of the points correlated with the terrain. Although the approach worked and gave good results, these were of

\begin{tabular}{|c|c|c|c|}
\hline Approach & Technology & Comment & Test/measurement \\
\hline EM & $\begin{array}{l}\text { Geophysical: } \\
\text { metal detector }\end{array}$ & $\begin{array}{l}\text { Will notify rescue team when they come } \\
\text { within a } 6 \mathrm{~m} \text { range of buried steel objects }\end{array}$ & $\begin{array}{l}\text { None required, but a good quality device needs } \\
\text { to accompany the rescue team }\end{array}$ \\
\hline GPR & $\begin{array}{l}\text { Geophysical: } \\
\text { Ground Penetrating } \\
\text { Analyzer GPR } 3000\end{array}$ & $\begin{array}{l}\text { Its } 25 \mathrm{~m} \text { range for detecting metal and } \\
\text { imaging shapes makes it a good option } \\
\text { for Lily mine }\end{array}$ & $\begin{array}{l}\text { Testing is required at a suitable site, e.g. Sterkfontein Caves } \\
\text { (test both surface and underground) }\end{array}$ \\
\hline $\begin{array}{l}\text { Electrical } \\
\text { resistivity }\end{array}$ & Geophysical & $\begin{array}{l}\text { This technique is useful for investigation } \\
\text { at relatively greater depths and provides } \\
\text { diverse data for stratigraphic, hydrological, } \\
\text { and geostructural information }\end{array}$ & $\begin{array}{l}\text { Testing is required at a site such as Sterkfontein Caves } \\
\text { for calibration / validation }\end{array}$ \\
\hline $\begin{array}{l}\text { IR } \\
\text { thermography }\end{array}$ & $\begin{array}{l}\text { Satellite images or } \\
\text { IR camera }\end{array}$ & $\begin{array}{l}\text { Considering that satellite data is affordable } \\
\text { and available, it should be considered. } \\
\text { The IR camera has potential, but is unlikely } \\
\text { to be a better option than satellite imagery }\end{array}$ & $\begin{array}{l}\text { Ordering of IR imagery for incorporation into a GIS system. } \\
\text { Satellite images preferred over the IR camera }\end{array}$ \\
\hline Microgravity & $\begin{array}{l}\text { Geophysical: } \\
\text { gravimeter }\end{array}$ & $\begin{array}{l}\text { Has potential, but unlikely to be a better } \\
\text { option than GPR }\end{array}$ & GPR preferred \\
\hline Seismic & Geophysical: TPL & $\begin{array}{l}\text { If the missing miners were still alive, this } \\
\text { method would have ranked highly. Under } \\
\text { the circumstances, however, GPR is a } \\
\text { better option }\end{array}$ & $\begin{array}{l}\text { GPR preferred, considering the fact that the trapped miners } \\
\text { are no longer alive }\end{array}$ \\
\hline Communications & HT or cell phone & $\begin{array}{l}\text { If the missing miners were still alive, calling } \\
\text { them would have been the best option. } \\
\text { Under the circumstances, however, tracking } \\
\text { the phones is the next best option }\end{array}$ & The technology to track cell phones is not available to the public \\
\hline
\end{tabular}




\section{Towards safer mining: scientific measurement approaches that could be applied}
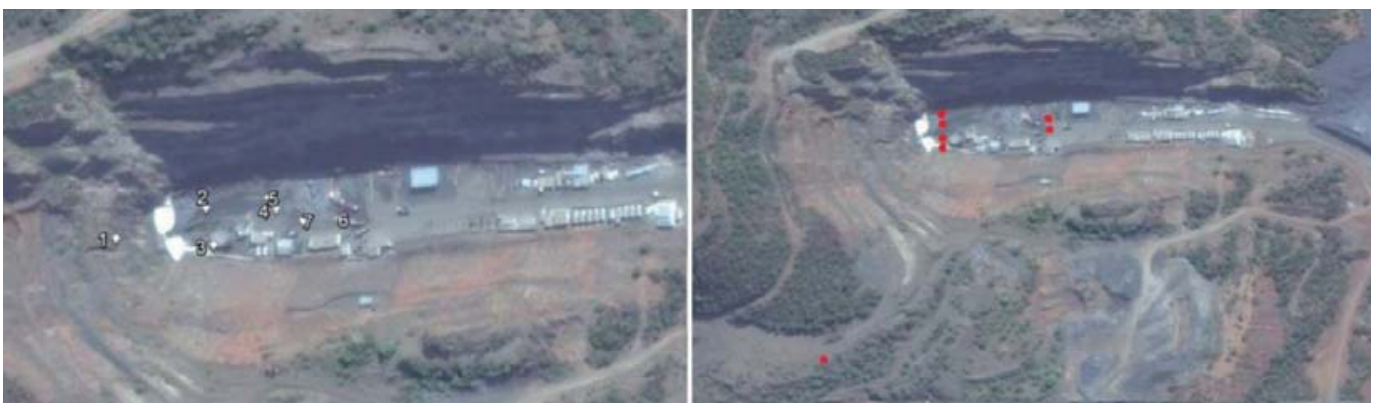

Figure 6-UAV surveyed points

little use, primarily because of the significant 'noise' as a result of the many buried steel objects and other surface infrastructure. In addition to the noise problem, the surface was considered too unsafe to allow detailed inspection of the target areas. The lessons for future rescue attempts are as follows.

> EM surveys are appropriate technologies for rescue operators and can be quickly deployed. Metal detectors are versatile technologies that can be operated through hand-held devices (both on surface and underground) and mounting on moving platforms like UAVs

> After the results have been processed and target areas identified, the EM surveys should be followed by either a visual inspection or using a camera mounted on the $\mathrm{UAV}$. If ground conditions are unstable, such inspections should be done from a UAV platform

> A good quality hand-held metal detector should accompany the rescue team underground to investigate target areas defined by software modelling (Ashraf and Cawood, 2016) and to warn rescue teams withdrawing loose rock containing steel objects (which could include the missing container in which the miners are) gravitating to withdrawal points.

\section{Seismic approach: TPL}

Mine Rescue Services used a TPL 310D (Mini TPL) in an effort to establish if anyone survived the disaster. This instrument can detect and pinpoint the location of trapped persons below and above the ground if they are alive and respond to knocking. It has two modes of operation, i.e. SURVEY and LOCATE. SURVEY is used on rescue sites to establish communication with trapped persons using acoustic sensors, if any living and conscious survivors are under the rubble. The system also provides a means to communicate with trapped persons. The acoustic sensor functions as a loudspeaker/microphone, which can be inserted into crevices and allows two-way communication to be established with the trapped persons. The LOCATE mode provides information about the location of the person, in or below the rescue site, so as to guide the rescue team. By moving the sensors around, trapped persons can be traced to within $5 \mathrm{~m}$ (Elpam Electronics Ltd., 2014). In the case of Lily mine, it was assumed that some trapped persons survived the initial disaster and were alive to provide a minimal response to calls or knockings from the rescue team. The TPL was used underground at level 5 and established a location in an 'East 1 ' direction of the sensor, but could not indicate inclination or distance. The technology has significant potential, and had it been used in conjunction with the communication devices of the missing miners, the position of the container could have been established with more certainty. The lessons for future rescue attempts are as follows.

> TPLs are very effective technologies for rescue operators and can be quickly deployed. As is the case with metal detectors, TPLs are versatile technologies that can be operated through hand-held devices (both on surface and underground)

> Attention should be given to the correct (full) use and (accurate) location of the device. This will help with plotting target areas on the mine plan

- A good quality TPL should accompany any rescue effort. More importantly, the operators must be trained in the correct and full use of the device and must have some knowledge of surveying principles so that readings can be projected onto the mine plans.

\section{Communications approach: HT or cell phone tracking}

This approach was not tested in the days after the Lily mine disaster, but has significant potential while the batteries are still charged. The chances of success would be enhanced if communication technology is combined with other technologies like a TPL. Although no inventory of items in the Lily Mine lamp-room was available, it was established that there was a HT, but batteries were dead because of the time lapse since the disaster.

The next option was to track the cell phones. The cell phone numbers and the names of the trapped workers were provided by the mine to MHSC on 10 March 2016. The cell phone numbers of the trapped workers were dialled, just to establish that the numbers were the correct ones. As an additional measure, the numbers were passed on to the service provider so that they could establish if tracking the location of the three phones was possible. They indicated that it would not be possible to establish the location of the phone if the batteries were run down, and some of the numbers provided were not linked to the trapped individuals. In addition to contacting the cell phone service provider, the SAPS (South African Police Service) was contacted for assistance. In their letter of response, dated 18 March 2016, they indicated that cell phones can be traced only when reported missing within 24 hours, and that in their opinion, it is not possible to trace a cell phone underground. This response requires further testing in preparation for future 


\section{Towards safer mining: scientific measurement approaches that could be applied}

mine disasters. The lessons for future rescue attempts are:

> In a connected world, it is highly likely that there will be some communicating device with trapped miners, especially if they were on surface at the time of the disaster. The likelihood of a successful outcome is greater early after the disaster, when the batteries of the devices still have power and when the communications approach is used in tandem with other devices, e.g. a TPL

> It is important to keep inventory records for all facilities, along with personal and work phone information - and have these available for rescue efforts

> The technology to track cell phones is not available to the public and cannot be tested. Lily mine will not be the last to have a disaster at the time when mine workers carry cell phones on them. Future rescue efforts will be assisted if the SAPS allows the technology to be tested for accuracy and the maximum depth it can record signals from persons trapped below the surface or rubble .

\section{Summary}

Underground mining is prone to accidents, sometimes even disasters. These accidents may cause fatalities, injuries, and also result in significant economic losses. Such an accident occurred at the Lily mine on 5 February 2016 when the crown pillar supporting the surface workings collapsed. The lamp-room container on surface, with three miners inside, subsided and was lost in the sinkhole along with two 550 kVA transformers, one generator, and two steel water tanks. This study discusses the role of technology for imaging and locating the buried objects in underground mine disasters, following a conceptual approach for detecting the lamp-room container at Lily mine. The technical aspects of potential technologies for imaging and locating subsurface utilities have been discussed, along with observations made during the testing of some of the technologies. Although the rescue efforts could not establish the location of the trapped miners, many lessons were learned. The purpose of this article is to record the lessons and advise on further testing and image modelling. This will not only assist with finding the Lily miners, but could be considered for future rescue operations.

\section{Recommendations}

In addition to what has been tested at Lily mine to date, it is important to also establish the application of IR data and GPR to mine disaster scenes. Its longer range (up to about $30 \mathrm{~m}$ ) for detecting metal and imaging shapes makes GPR a good option for Lily mine, but the effectiveness should be tested at a suitable site elsewhere, e.g. Sterkfontein Caves, where tests could be conducted both on surface and underground. The combination of IR and GPR technologies can possibly establish the depth, location, and shape of the target.

The following aspects should be considered by the authorities in order to speed up future mine rescue operations.

> The communications approach has significant potential for a successful outcome, but speed is important and the options will run out quickly when the batteries of the devices lose their power

> Obtain permission from the SAPS to conduct scientific tests on the technology for tracking cell phones in the event of a mine disaster. Tests are required to establish the accuracy and the maximum depth to which the technology can receive signals from below the surface or rubble

> A TPL should accompany any rescue effort, but it is essential that the operator is trained in the correct use of the device and has some knowledge of surveying principles so that readings can be projected onto the mine plans

> A good quality hand-held metal detector should accompany the rescue team and the team should be trained in its operational principles, functionality and limitations, and the correct use of the device

> Inventory records should be kept for all facilities, along with personal and work phone information - and these should be available for rescue efforts

> It is recommended that, where surface infrastructure is established over undermined ground, a risk assessment should be conducted and such infrastructure be made 'intelligent' through the installation of either an EMS or a basic TTE communication system. The electronic marker consists of passive radio frequency identification (RFID) system for locating both metallic and nonmetallic objects, whereas the TTE communication system is useful in disasters for locating miners trapped underground.

\section{References}

3M Infrastructure Protection Division. 2012. 3M M ${ }^{\mathrm{TM}}$ Electronic Marker System (EMS) Full-Range Markers.

http://solutions.3m.com/3MContentRetrievalAPI/BlobServlet?lmd=135222 0294000\&locale $=$

en_WW\&assetType=MMM_Image\&assetId $=1319241427287 \&$ blobAttribut e=ImageFile [accessed 22 July 2016].

Advanced Geosciences, Inc. 2016. Historic cemetery, Texas; Archeological grave site location. http://www.agiusa.com/historic-cemetery-texas [accessed 29 September 2016].

American Society of Civil EngineERs. 2002. Standard guidelines for the collection and depiction of existing subsurface utility data. Report no. CI/ASCE 3802. ASCE Codes and Standards Activity Committee (CSAC), New York.

AMPROBE. n.d. Underground pipe and cable locator. http://www.amprobe.com/ amprobe/usen/wire-tracers-underground-cable-and-cablelocators/underground-cable-and-pipe-locators-/amp-at5000.htm?pid=73171 [accessed 25 July 2016]

AshraF H. and CAWood F.T. 2018. Towards safer mining: the role of modelling software to detect the container in which the Lily miners were trapped. Mining of Mineral Deposits. (Accepted for publication).

Bandyopadhyay, L.K., Chaulya, S.K., and Mishra, P.K. 2010. Wireless Communication in Underground Mines: RFID-based Sensor Networking. Springer, New York, Dordrecht, Heidelberg, London.

Benson, R., Glaccum, R.A., and Noel, M.R. 1984. Geophysical techniques for sensing buried wastes and waste migration. Report no. EPA-600/7-84064. US Environmental Protection Agency, Environmental Monitoring Systems Laboratory, Las Vegas, NV.

Dodge, L.J. and AnSPACH, J.H. 1995. Case study of an environmental assessment combining historical practices and subsurface utility engineering. Proceedings of the 57th American Power Conference, Chicago, IL, 18-20 April 1995. International Nuclear Information System, IAEA, vol. 57, no. II. pp. $870-873$. 


\section{Towards safer mining: scientific measurement approaches that could be applied}

ElPAM Electronics LTd. 2014. TPL 310D-Mini Trapped Person Locator. http://www.elpam.com/products/search-rescue/tpl-310d-mini-trappedperson-locator/ [accessed 15 June 2016]

Hussain I., CAwood F., AND OLST R.V. 2017. Effect of tunnel geometry and antenna parameters on through-the-air communication systems in underground mines: Survey and open research areas. Physical Communication (Elsevier), vol. 23. pp. 84-94. ISSN 1874-4907.

INNOGEO. 2013. Microgravimetry to search for underground cavities, subsidence, galleries, decompressed zones. http://www.innogeo.fr/english/wp content/uploads/sites/7/2014/01/TD-microgravimetry.pdf [accessed 21 March 2016].

Jeong, H.S., Arboleda, C.A., Abraham, D.M., Halpin, D.W., and Bernold, L.E. 2003. Imaging and locating buried utilities. Technical Report no. FHWA/IN/JTRP-2003/12. National Technical Information Service Springfield, VA.

JusoH, Z. 2010. Application of 2-D resistivity imaging and seismic refraction technique in subsurface investigation for civil engineering. MS thesis, School of Physics, Science University, Penang, Malaysia.

KHATRI,R., SHRivastava, V.K., and CHAndaK, R. 2011. Correlation between vertical electric sounding and conventional methods of geotechnical site investigation. International Journal of Advanced Engineering Sciences and Technologies, vol. 4, no. 2. pp. 42-53

KTS-ELECTRONIC. 2016. Ground Penetrating Analyzer: GPA 3000. http://ktselectronic.com/en/ground-penetrating-analyzer-gpa-3000.html [accessed 21 March 2016].
LoKE, M.H. 1999. Electrical imaging surveys for environmental and engineering studies: A practical guide to 2-D and 3-D surveys, http://www.geo.mtu.edu/ ctyoung/LOKENOTE.PDF [accessed 2 June 2016].

MARIITA, N.O. 2007. The gravity method. Short Course II on Surface Exploration for Geothermal Resources, organized by UNU-GTP and KenGen, Lake Naivasha, Kenya, 2-17 November 2007.

Michael, R.Y., GeRAld, T.H., Nicholas, W.D., and Justin, R.S. 2012. NIOSHsponsored research in through-the-earth communications for mines: a status report. IEEE Transactions on Industry Applications, vol. 48, no. 5 . pp. $1700-1707$

Mine Safety and Health Administration. 2010. "Are You Prepared?" Mine emergency preparedness and response initiative. http://arlweb.msha.gov/focuson/areyouprepared /MineEmergency.asp [accessed 5 April 2016].

SATELlite IMAGing CoRPoRATion. 2013. Mineral exploration and mining. http://satimagingcorp.tw.cn/svc/mining.html [accessed 10 June 2016].

STARK, A. 2008. Seismic Methods and Applications: A Guide for the Detection of Geologic Structures, Earthquake Zones and Hazards, Resource Exploration, and Geotechnical Engineering. BrownWalker Press, Boca Raton, FL.

SubSuRface Surveys \& Associates, Inc. n.d. Geophysical methods $\&$ applications. http://www.subsurfacesurveys.com/pdf/Methods.pdf [accessed 19 March 2016].

WoRKSWELl. 2016. Thermal Vision Pro. http://www.drone-thermalcamera.com/thermal-vision-pro/ [accessed 26 March 2016] 